\title{
Development of Wastewater Treatment Technique by Catalytic Oxidation in Superheated Steam
}

\author{
Atsushi WATANABE ${ }^{1}$, Idzumi OKAJIMA ${ }^{1 *}$, Takeshi $\mathrm{SAKO}^{2}$, Makoto TSUKIJI ${ }^{3}$, Takamasa KATO ${ }^{3}$, and Akiyoshi \\ $\mathrm{ODA}^{3}$ \\ ${ }^{1}$ Graduate School of Integrated Science and Technology, Shizuoka University, 3-5-1 Johoku, Naka-ku, Hamamatsu, Shizuoka 432- \\ 8561, Japan \\ ${ }^{2}$ Graduate School of Science and Technology, Shizuoka University, 3-5-1 Johoku, Naka-ku, Hamamatsu, Shizuoka 432-8561, Japan \\ ${ }^{3}$ Nippon Refine Co., Ltd, 2-2-1 Marunouchi, Chiyoda-ku, Tokyo, 100-0005, Japan
}

\begin{abstract}
The purpose of this research was the development of a wastewater treatment technique using catalytic oxidation in superheated steam. The target substance was isopropyl alcohol (IPA). The experiment was carried out using a plug-flow reactor filled with $\mathrm{MnO}_{2}$ catalyst. The optimum decomposition condition was determined, and the kinetics of the catalytic oxidation reaction were analyzed. The experimental results were expressed as total organic carbon (TOC) removal. The dependences of the TOC removal on the reaction temperature and residence time were investigated. The TOC removal increased with the reaction temperature and residence time. It was $99.8 \%$ at $300^{\circ} \mathrm{C}, 0.9 \mathrm{MPa}, 11 \mathrm{~s}$, and oxidant ratio of 1.2 . On the other hand, the TOC removal was constant for a long residence time at low reaction temperatures of 200 and $230^{\circ} \mathrm{C}$. This was because acetone and acetic acid were produced via the oxidation of IPA, and they were detected as TOC. The reaction kinetics were examined using the pseudo-first-order reaction model; the TOC removal correlated well with this model. Based on the results of the kinetics, the activation energy $\left(E_{\mathrm{a}}\right)$ for TOC decomposition was determined from the Arrhenius equation; it was 56.1 $\mathrm{kJ} / \mathrm{mol}$. These results indicate that catalytic oxidation in superheated steam is useful for wastewater treatment.
\end{abstract}

\section{Introduction}

In semiconductor manufacturing, cleaning and drying processes are carried out to remove organic substances. The organic solvent used in these processes is amphiphilic, and a high-purity solvent is used. However, the recovered organic solvent is not high purity, and its reuse is difficult. Therefore, the wastewater is generally treated using the activated sludge method. However, this method has problems such as a long treatment time, the necessity of pre-treatment and post-treatment, and the generation of excess sludge. Therefore, a wastewater treatment technique with a short time and less environmental load is required.

Figure 1 shows the phase diagram of water. In the hydrothermal oxidation method, supercritical water and subcritical water are often used. The supercritical water oxidation (SCWO) method exhibits excellent treatment ability, allowing clean and efficient decomposition of many aqueous organic wastes. Sanchez-Oneto et al. (2007). studied the decomposition of different cutting fluids (Biocut and Servol) in supercritical water. The operating temperatures were $673-773 \mathrm{~K}$ for a wide range of residence times of 6-105 s. As a result, SCWO of both the cutting fluids achived more than $95 \%$ removal of both the chemical oxygen demand (COD) and total organic carbon (TOC) at $773 \mathrm{~K}$. Sogut and Akgun (2007) studied a model azo dye pollutant (CI Disperse Orange 25) using SCWO in a plug-flow reactor. They achieved a removal of up to $98.52 \%$ in very short residence times of 4-12 s.

Table 1 shows the conditions for hydrothermal oxidation. The SCWO method has the drawback of severe conditions. Hence, catalytic oxidation in superheated steam is attracting attention as a new wastewater treatment technique. Cost reduction for the equipment can be expected because superheated steam oxidation is a lowtemperature and low-pressure process compared with SCWO.

However, to the best of our knowledge, the oxidation reaction kinetics of wastewater in superheated steam with a catalyst has not been reported. The purpose of this research was to investigate the decomposition and analyze the kinetics. In this study, an aqueous solution of isopropyl alcohol (IPA) was selected as a model for wastewater under superheated steam conditions.

\footnotetext{
*Corresponding author: okajima.izumi $@$ shizuoka.ac.jp
} 
Table 1. Conditions for hydrothermal oxidation

\begin{tabular}{cc}
\hline Method & Condition \\
\hline SCWO & $\mathrm{T} \geqq 374{ }^{\circ} \mathrm{C}\left(\mathrm{T}_{\mathrm{C}}\right)$ and $\mathrm{P} \geqq 22.1 \mathrm{MPa}\left(\mathrm{P}_{\mathrm{C}}\right)$ \\
Superheated & $100^{\circ} \mathrm{C}<\mathrm{T}<\mathrm{T}_{\mathrm{C}}$ and $\mathrm{P}<\mathrm{P}_{\mathrm{S}}$ \\
steam oxidation & $\mathrm{T} \geqq \mathrm{T}_{\mathrm{C}}$ and $\mathrm{P} \leqq \mathrm{P}_{\mathrm{C}}$ \\
\hline
\end{tabular}



Figure 1. Phase diagram of water

\section{Experimental}

\subsection{Apparatus}

Figure 2 shows a plug-flow reactor. The two feed streams were pumped in different lines and only the $\mathrm{H}_{2} \mathrm{O}_{2}$ solution feed stream was preheated. A syringe pump (Model 500D, Teledyne Isco, USA) and a plunger pump (Model L-6000, Hitachi, Japan) were used to pump the feed to the reactor at the required flow rate, which depended on the required residence time (5-30 s) in the reactor. The reactor used was a type-316 stainless steel tube with the following dimensions: 1 in. diameter; $2.1 \mathrm{~mm}$ thickness; and $1 \mathrm{~m}$ length. The central part $(86 \mathrm{~cm})$ of the reactor was filled with $\mathrm{MnO}_{2}$ particles as catalyst. Other spaces of the reactor were filled with $3 \mathrm{~mm} \varphi \alpha$-alumina balls. The preheating coil for $\mathrm{H}_{2} \mathrm{O}_{2}$ aqueous solution was made of a $1 / 8$ in. spiral tube of type- 316 stainless steel with a length of $4 \mathrm{~m} . \mathrm{H}_{2} \mathrm{O}_{2}$ was used as the oxidant source and it was completely decomposed to oxygen and water in the preheater section. After preheating, oxygen and the model wastewater were reacted on the $\mathrm{MnO}_{2}$ catalyst. The effluent from the reactor was rapidly cooled using a cooling coil placed in a water bath. The effluent was depressurized using a back-pressure regulator, and the liquid sample was recovered using pure water.

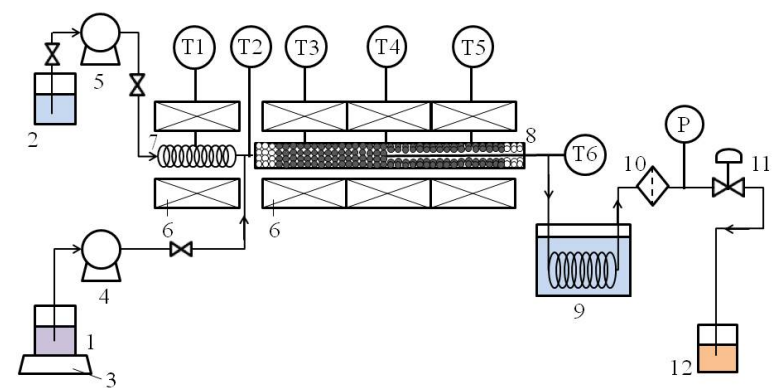

1. IPA solution 2. Hydrogen peroxide solution 3. Electronic balance

4. High-pressure pump 5. Syringe pump 6. Electric furnaces 7. Preheater

8. Reactor 9. Cooler 10. Filter 11. Back-pressure regulator 12. Trap bottle

$\mathrm{T} 1$ - T6. Thermometers P. Pressure gauge $\mathrm{O}$ a-aluminaball - $\mathrm{MnO}_{2}$ catalyst

Figure 2. Experimental apparatus

\subsection{Materials}

IPA $\left(\mathrm{C}_{3} \mathrm{H}_{8} \mathrm{O}, 99.7 \%\right.$ purity, FUJIFILM Wako Pure Chemical, Japan) was prepared as the model wastewater such that the concentration of the IPA aqueous solution was $0.5 \mathrm{wt} \%$ at the reactor inlet. $\mathrm{H}_{2} \mathrm{O}_{2}$ aqueous solution (30wt\%, FUJIFILM Wako Pure Chemical, Japan) was prepared as the oxidant source such that the oxidant ratio was $1.2 . \mathrm{MnO}_{2}$ catalyst shows high catalytic activity and stability in SCWO. In this study, we used $\mathrm{MnO}_{2}$ (min. $70.0 \%$ assay, particulates, FUJIFILM Wako Pure Chemical, Japan) as the catalyst in the reaction.

\subsection{Calculation of residence time}

The residence time $(t)$ in the reactor packed with the $\mathrm{MnO}_{2}$ catalyst was calculated using the following equation:

$t[s]=\frac{\text { Void volume in the catalyst layer }[\mathrm{mL}]}{\text { Flow rate of mixed gas }[\mathrm{mL} / \mathrm{s}]}$

The $\mathrm{O}_{2}$, water, and IPA flowing in the reactor were regarded as a mixed gas, and the flow rate was calculated from the physical properties at the reaction conditions.

\subsection{TOC removal}

TOC removal $\left(X_{\mathrm{TOC}}\right)$ was used to evaluate the decomposition efficiency of catalytic oxidation in superheated steam, and it was defined as follows:

$X_{\text {TOC }}[-]=1-\frac{\text { Remaining TOC }[\mathrm{g}]}{\text { TOC in supplied IPA solution }[\mathrm{g}]}$

In this study, the condition of $99.5 \%$ was taken as the optimum decomposition condition.

\subsection{Oxidant ratio}

The oxidant ratio was defined as follows:

Oxidant ratio $[-]=\frac{\mathrm{O}_{2} \text { supplied to the reactor }[\mathrm{mol}]}{\text { Stoichimetric amout of } \mathrm{O}_{2}[\mathrm{~mol}]}$ 
The oxidant ratio was 1.2, so that the TOC in IPA was completely oxidized.

\subsection{Analysis}

The liquid samples from the reactor were evaluated by analyzing the TOC concentration. TOC analysis was performed using a TOC-V CPH (Shimadzu, Japan). To obtain accurate date, the samples were analyzed in duplicate; the averages are reported as the results.

\section{Results and Discussion}

\subsection{Effects of reaction temperature and residence time}

In this study, the effects of the reaction temperature and residence time on the catalytic oxidation of IPA in superheated steam were investigated.

Figure 3 shows the reaction temperature and residence time dependences of the TOC removal by catalytic oxidation in superheated steam. The TOC removal increased with the reaction temperature and residence time. It was $99.8 \%$ at $300^{\circ} \mathrm{C}, 0.9 \mathrm{MPa}, 11 \mathrm{~s}$, and an oxidant ratio of 1.2. On the other hand, the TOC removal was constant for a long residence time at low reaction temperatures of 200 and $230^{\circ} \mathrm{C}$. This was because acetone and acetic acid were produced via the oxidation of IPA and $\mathrm{C}-\mathrm{C}$ bond cleavage. It is presumed that the oxidation decomposition rate of TOC decreases because acetone has the same amount of carbon as that in IPA, and acetic acid is stable.

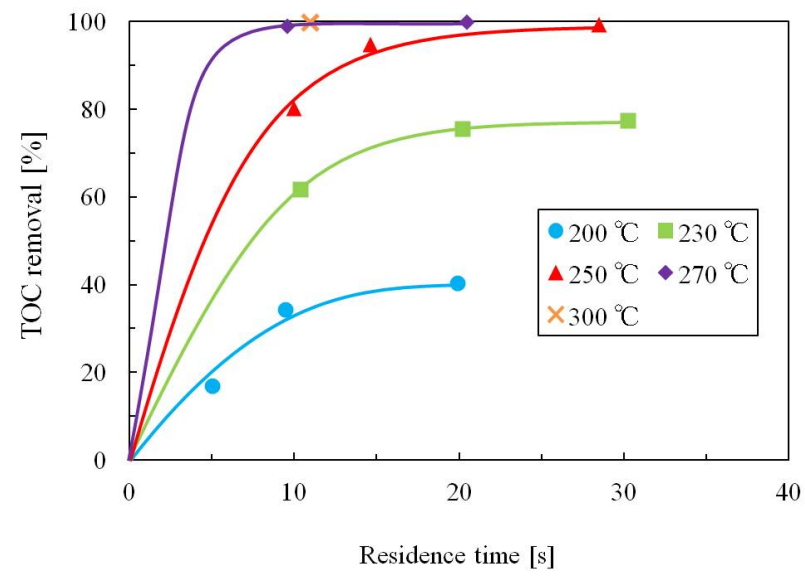

Figure 3. Reaction temperature and residence time dependences of TOC removal by catalytic oxidation in superheated steam at $0.9 \mathrm{MPa}$ and oxidant ratio of 1.2

\subsection{Kinetics analysis}

The global reaction rate for the decomposition of TOC via hydrothermal oxidation can be expressed as follows:

$-\frac{\mathrm{d}[\mathrm{TOC}]}{\mathrm{d} t}=k[\mathrm{TOC}]^{\alpha}\left[\mathrm{O}_{2}\right]^{\beta}\left[\mathrm{H}_{2} \mathrm{O}\right]^{\gamma}$ where $[\mathrm{TOC}]$ is the reactant concentration $(\mathrm{mol} / \mathrm{L}),\left[\mathrm{O}_{2}\right]$ is the $\mathrm{O}_{2}$ concentration $(\mathrm{mol} / \mathrm{L}),\left[\mathrm{H}_{2} \mathrm{O}\right]$ is the $\mathrm{H}_{2} \mathrm{O}$ concentration $(\mathrm{mol} / \mathrm{L}), t$ is the residence time, $k$ is the reaction rate constant, and $\alpha, \beta$, and $\gamma$ are the reaction orders of TOC, $\mathrm{O}_{2}$, and $\mathrm{H}_{2} \mathrm{O}$, respectively.

In this study, kinetics analysis was performed using the pseudo-first-order reaction model. $\mathrm{H}_{2} \mathrm{O}$ was present in excess as superheated steam. In addition, $\mathrm{O}_{2}$ was present in excess because the oxidant ratio was 1.2. As a result, the reaction order of $\mathrm{H}_{2} \mathrm{O}$ and $\mathrm{O}_{2}$ was assumed to be $0(\beta=\gamma$ $=0)$. In the pseudo-first-order reaction model, the reaction order of TOC was assumed to be $1(\alpha=1)$. From Eq. (4), the following simplified equation was obtained:

$-\frac{\mathrm{d}[\mathrm{TOC}]}{\mathrm{d} t}=k[\mathrm{TOC}]$

Integrating Eq. (5) and using $X_{\mathrm{TOC}}$, a relationship Eq. (6) between the TOC removal and residence time was obtained.

$-\ln \left(1-X_{\mathrm{TOC}}\right)=k t$

Figure 4 shows the kinetics of IPA decomposition via catalytic oxidation in superheated steam. The reaction correlated well with the pseudo-first-order reaction model Using kinetics analysis, the reaction rate constants at each reaction temperature were obtained.

The temperature dependence of the reaction rate constants was expressed by the Arrhenius equation:

$k=A \exp \left(-\frac{E_{a}}{R T}\right)$

where $A$ is the frequency factor $\left(\mathrm{s}^{-1}\right), E_{\mathrm{a}}$ is the activation energy $(\mathrm{J} / \mathrm{mol}), R$ is the universal gas constant $(\mathrm{J} /(\mathrm{mol} \cdot$ $\mathrm{K})$, and $T$ is the reaction temperature $(\mathrm{K})$. The logarithmic form of Eq. (7) is as follows:

$\ln k=-\frac{E_{\mathrm{a}}}{R T}+\ln A$

Figure 5 shows the Arrhenius plot of IPA decomposition via catalytic oxidation in superheated steam. $E_{\mathrm{a}}$ was 56.1 $\mathrm{kJ} / \mathrm{mol}$ and $A$ was $6.17 \times 10^{4} \mathrm{~s}^{-1}$. Table 2 shows the reaction rate constants at each reaction temperature and the activation energy. Furthermore, the global rate expression for catalytic oxidation of IPA in superheated steam is as follows:

$-\frac{\mathrm{d}[\mathrm{TOC}]}{\mathrm{d} t}=6.17 \times 10^{4} \cdot \exp \left(-\frac{56.1 \times 10^{3}}{R T}\right) \cdot[\mathrm{TOC}]$

From previous research, it is known that the activation energy of IPA in SCWO is $133.5 \mathrm{~kJ} / \mathrm{mol}$ (Abelleira, 2013). It is presumed that the activation energy in this study is lower due to the catalytic action. Owing to efficient contact of the activated TOC with $\mathrm{O}_{2}$ on the catalyst surface, the reaction proceeds with low energy.

In Figure 6, the $X_{\text {TOC }}$ predicted using Eq. (9) are plotted against the experimental values obtained in this study. The average relative error between the predicted and experimental $X_{\mathrm{TOC}}$ was $8.52 \%$, which was a good agreement. 
Table 2. Reaction rate constants at each reaction temperature and activation energy

\begin{tabular}{ccc}
\hline$T\left[{ }^{\circ} \mathrm{C}\right]$ & $k\left[\mathrm{~s}^{-1}\right]$ & $E_{\mathrm{a}}[\mathrm{kJ} / \mathrm{mol}]$ \\
\hline 200 & 0.0426 & \\
230 & 0.0743 & 56.1 \\
250 & 0.176 & \\
\hline
\end{tabular}

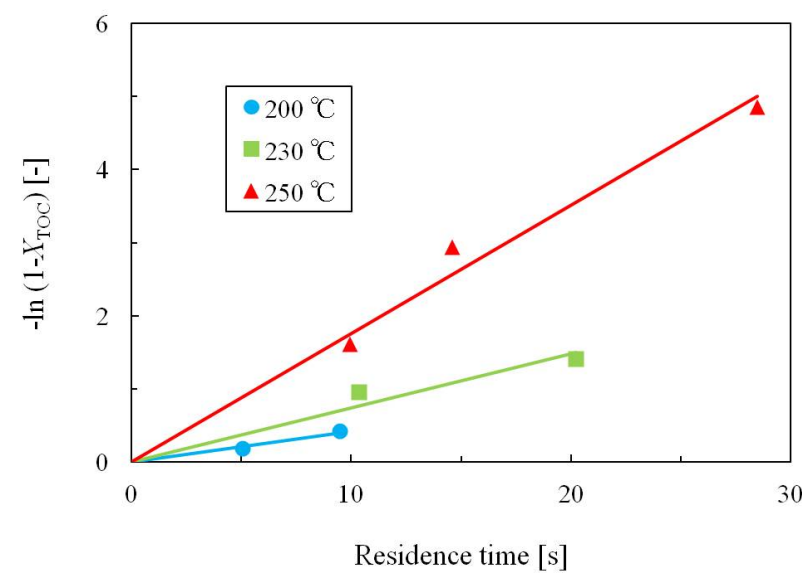

Figure 4. Kinetics of IPA decomposition by catalytic oxidation in superheated steam at $0.9 \mathrm{MPa}$ and oxidant ratio of 1.2

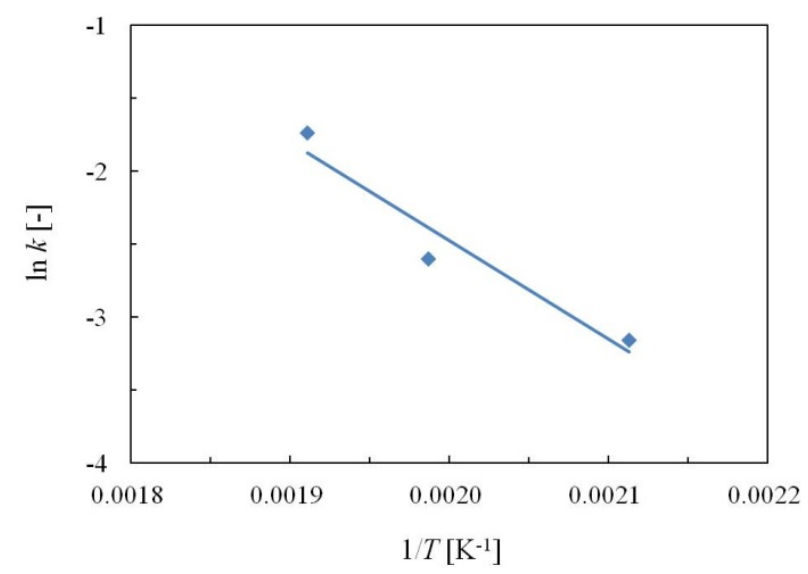

Figure 5. Arrhenius plot of IPA decomposition by catalytic oxidation in superheated steam at $0.9 \mathrm{MPa}$ and oxidant ratio of 1.2

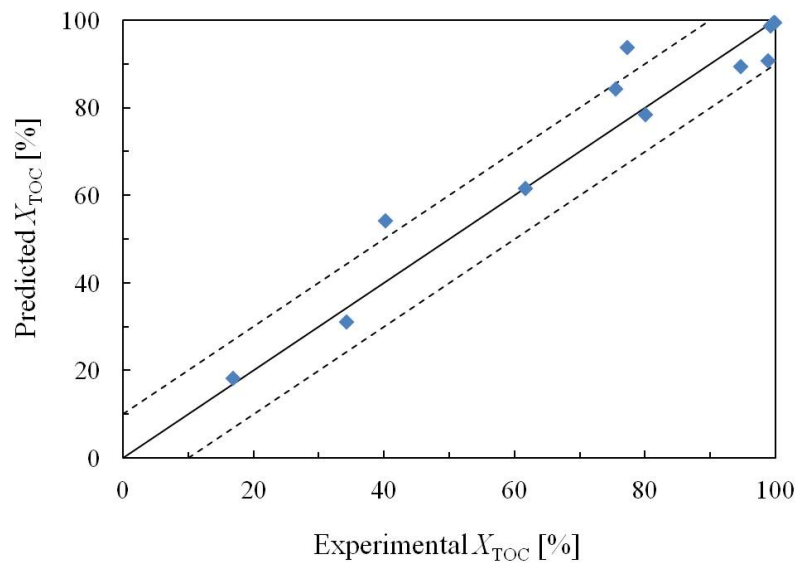

Figure 6. Comparison between predicted and experimental $X_{\mathrm{TOC}}$

\section{Conclusions}

Catalytic oxidation of IPA in superheated steam was carried out using a plug-flow reactor filled with $\mathrm{MnO}_{2}$ catalyst. The TOC removal achieved was $99.8 \%$ at $300^{\circ} \mathrm{C}$, $0.9 \mathrm{MPa}, 11 \mathrm{~s}$, and an oxidant ratio of 1.2.

Kinetics analysis showed that the reaction correlated well with the pseudo-first-order reaction model. According to the Arrhenius plot, the activation energy was $56.1 \mathrm{~kJ} / \mathrm{mol}$. The average relative error between the TOC removal predicted using the global rate expression, and the experimental values was $8.52 \%$.Therefore, the TOC removal at any residence time can be estimated using the global rate expression.

\section{References}

Abelleira, J., J. Sanchez-Oneto, J. R. Portela, and E. Martinez de la Ossa; "Kinetics of Supercritical Water Oxidation of Isopropanol as an Auxiliary Fuel and Cofuel,"Fuel, 111, 574-583 (2013)

Sanchez-Oneto, J., J. R. Portela, E. Nebot, and E. Martinez de la Ossa; "Hydrothermal Oxidation: Application to the Treatment of Different Cutting Fluid wastes," Journal of Hazardous Materials, 144, 639-644 (2007)

Sogut, O. and M. Akgun; "Treatment of Textile Wastewater by SCWO in a Tube Reactor," The Journal of Supercritical Fluids, 43, 106-111 (2007) 